\title{
Statistical prediction of far-field wind-turbine noise, with probabilistic characterization of atmospheric stability
}

\author{
Kelly, Mark C.; Barlas, Emre; Sogachev, Andrey
}

Published in:

Journal of Renewable and Sustainable Energy

Link to article, DOI:

$10.1063 / 1.5012899$

Publication date:

2018

Document Version

Publisher's PDF, also known as Version of record

Link back to DTU Orbit

Citation (APA):

Kelly, M. C., Barlas, E., \& Sogachev, A. (2018). Statistical prediction of far-field wind-turbine noise, with probabilistic characterization of atmospheric stability. Journal of Renewable and Sustainable Energy, 10(1), [013302]. https://doi.org/10.1063/1.5012899

\section{General rights}

Copyright and moral rights for the publications made accessible in the public portal are retained by the authors and/or other copyright owners and it is a condition of accessing publications that users recognise and abide by the legal requirements associated with these rights.

- Users may download and print one copy of any publication from the public portal for the purpose of private study or research.

- You may not further distribute the material or use it for any profit-making activity or commercial gain

- You may freely distribute the URL identifying the publication in the public portal 
Statistical prediction of far-field wind-turbine noise, with probabilistic characterization of atmospheric stability

Mark Kelly, Emre Barlas, and Andrey Sogachev

Citation: Journal of Renewable and Sustainable Energy 10, 013302 (2018);

View online: https://doi.org/10.1063/1.5012899

View Table of Contents: http://aip.scitation.org/toc/rse/10/1

Published by the American Institute of Physics 


\title{
Statistical prediction of far-field wind-turbine noise, with probabilistic characterization of atmospheric stability
}

\author{
Mark Kelly, ${ }^{1, a)}$ Emre Barlas, $^{2}$ and Andrey Sogachev ${ }^{1}$ \\ ${ }^{1}$ Wind Energy Department, Ris $\varnothing$ Lab/Campus, Danish Technical University, \\ Frederiksborgvej 399, Roskilde 4000, Denmark \\ ${ }^{2}$ Wind Energy Department, Lyngby Campus, Danish Technical University, Lyngby 2800, \\ Denmark
}

(Received 8 November 2017; accepted 14 December 2017; published online 10 January 2018)

\begin{abstract}
Here we provide statistical low-order characterization of noise propagation from a single wind turbine, as affected by mutually interacting turbine wake and environmental conditions. This is accomplished via a probabilistic model, applied to an ensemble of atmospheric conditions based upon atmospheric stability; the latter follows from the basic form for stability distributions established by Kelly and Gryning [BoundaryLayer Meteorol. 136, 377-390 (2010)]. For each condition, a parabolic-equation acoustic propagation model is driven by an atmospheric boundary-layer ("ABL") flow model; the latter solves Reynolds-Averaged Navier-Stokes equations of momentum and temperature, including the effects of stability and the ABL depth, along with the drag due to the wind turbine. Sound levels are found to be highest downwind for modestly stable conditions not atypical of mid-latitude climates, and noise levels are less elevated for very stable conditions, depending on ABL depth. The probabilistic modelling gives both the long-term (ensemble-mean) noise level and the variability as a function of distance, per site-specific atmospheric stability statistics. The variability increases with the distance; for distances beyond $3 \mathrm{~km}$ downwind, this variability is the highest for stability distributions that are modestly dominated by stable conditions. However, mean noise levels depend on the widths of the stable and unstable parts of the stability distribution, with more stably-dominated climates leading to higher mean levels. Published by AIP Publishing. https://doi.org/10.1063/1.5012899
\end{abstract}

\section{INTRODUCTION}

Noise emitted from wind turbines can be a major concern for residents living nearby and is subsequently an important consideration for the viability of potential wind farms. Turbineassociated sound levels may vary considerably due to the differing atmospheric conditions that occur, from, e.g., day to night and season to season. Both the long-term mean and the standard deviation of the sound pressure level (SPL) are thus of interest for windfarm planning and associated tasks, where "long-term" connotes the lifetime of a wind farm, spanning two or more decades. As part of a 2016 internal cross-sectional initiative on wind turbine noise propagation at Danish Technical University (DTU), we developed a statistical model to predict the aforementioned SPL statistics. This model-along with models for turbine noise-source, propagation, and atmospheric flow-accounts for sound propagation from turbine blades through an ensemble of simulated atmospheres, incorporating both the stability (buoyancy) and the wind turbine wake. Here, we first introduce the various components of the problem.

\section{A. Medium-range outdoor sound propagation}

Sound propagation through the atmospheric boundary layer (ABL), for distances over which turbine noise is relevant (on the order of hundreds of meters to several kilometers, which

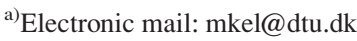


we refer to here as the "medium-range"), is a complex phenomenon that is influenced by a number of potentially competing effects. These include geometric spreading, atmospheric (molecular) absorption, attenuation, and reflection by the ground, as well as spatio-temporal variations in the speed of sound. Theoretical, ${ }^{1-5}$ numerical, ${ }^{6-8}$ and experimental ${ }^{2,9-11}$ works have shown that due to the last aspect, some atmospheric conditions can result in far-field SPL that may exceed the noise levels predicted when considering only geometric spreading, atmospheric absorption, and ground effects. From field measurements, it is clear that wind farm noise can be exceedingly higher than such predictions. ${ }^{12,13}$ This relative increase in SPL-particularly its aggregate effect on long-term low-order statistics-is not well-quantified with extant noise models or tools.

\section{B. Stability and the atmospheric boundary layer}

The primary contributors to fluctuations in the speed of sound are local fluctuations in the wind velocity and temperature fields (e.g., Embleton ${ }^{14}$ and Salomons ${ }^{15}$ ). Each velocity and temperature field can be decomposed in terms of a "background" profile which varies in the vertical plus three-dimensional turbulent (local) fluctuations. ${ }^{16}$ The background profiles are considered constant for $10 \mathrm{~min}$ or longer (up to perhaps $\sim 1 \mathrm{~h}$ according to stationarity in the $\mathrm{ABL}^{16,17}$ ), while the turbulent fluctuations vary over timescales ranging from seconds to minutes. The latter are generally responsible for acoustic scattering and SPL fluctuations over timescales of minutes or shorter, while a given stability condition is associated with background profiles of temperature and wind speed-and thus the short-term mean (background) sound speed profile, which we denote $c(z)$. Here, we are interested in long-term representative statistics, and so, we focus on modelling the sound speed profile, via atmospheric stability, as elucidated below. The sound speed profile is affected by vertical gradients in both the wind speed (shear) and the temperature (lapse rate); the ABL "top," which is characterized by a strong positive temperature gradient, can occur at heights ranging from $\sim 100$ to $200 \mathrm{~m}$ (winter/nighttime) up to $1 \mathrm{~km}$ or more (sunny day), with shallow ABLs having a dramatic impact on both the turbine wake structure and the sound propagation.

\section{Use of Reynolds-averaged Navier-Stokes (RANS) for ABL flows with wind turbines}

It has been shown that the wake in neutral conditions affects the propagation (from a single point source) through its impact on the wind profile. ${ }^{18}$ Thus, we model the flow field encountered by a wind turbine, also including the turbine wake, as affected by atmospheric stability (buoyancy). We aim to characterize the resultant multi-dimensional velocity and temperature fields for use as input to our acoustic propagation calculations. A computational method which allows such modelling is the numerical solution of the Reynolds-Averaged Navier-Stokes (RANS) equations. RANS solvers adapted for the atmospheric boundary layer can give the mean flow field for a given stability condition, including the variation of temperature and wind gradients in space. ${ }^{19}$ The buoyancy-affected gradients, in turn, both are affected by and modify the turbine wake; such interacting effects of a turbine on the flow are also readily modeled within RANS (e.g., Sharpe,$^{20}$ Troldborg et al., ${ }^{21}$ and Crasto et al. ${ }^{22}$ ). The solver that we use, SCADIS (SCAlar-DIStribution), ${ }^{23}$ also gives realistic ABL depths for a given surface-layer stability; ${ }^{19,24}$ both are important for establishing the vertical gradients which cause acoustic refraction and ultimately affect the transmission loss (TL).

\section{Statistical aspect}

In the lower $\mathrm{ABL}$ where wind turbines exist, given the importance of wind shear and vertical temperature gradients in the sound speed profile, the state of the atmosphere can be characterized by the surface-layer stability ${ }^{25,26}$ and also the ABL depth (height of temperature inver$\operatorname{sion}^{16,27}$ ). But the climatological effect of stability on the mean vertical profiles-and consequently on long-term means and variability-depends on the distribution of stability ${ }^{28,29}$ (and to a lesser extent also on the distribution of the ABL depth). Here, we adopt the 
probabilistic framework of Kelly and Gryning, ${ }^{29}$ which gives a form for universal stability distributions, allowing them to be expressed through long-term statistics. Thus, e.g., multi-year low-order noise-level statistics (mean and variance) are composed of an ensemble of noise fields, where each member of the ensemble corresponds to a representative atmospheric condition; the probability of each condition dictates the relative contribution of the noise field in that condition to the long-term noise statistics.

\section{E. Propagation modeling}

The ISO-9613-2 standard $^{30}$ includes a parameterization for meteorological (stability) effects; however, it is crude (does not depend on actual stability) and only has a valid range of wind speeds up to $5 \mathrm{~m} / \mathrm{s}$ - below the wind speeds relevant for wind turbines. ${ }^{31}$ Improvements on the ISO-9613-2, such as the Nord $2000^{32}$ and HARMONOISE ${ }^{33}$ models, have been made by building upon ray-tracing approaches. But these do not address some important factors, such as the Nord2000 model's lack of range-dependent sound-speed profiles or HARMONOISE model's neglect of multiple ground reflections; ${ }^{34}$ the former is relevant due to wind-turbine wakes, and the latter is an issue in winter and nighttime (stable) conditions. Further, these models do not readily facilitate the prediction of variability per observable stability statistics (again, we are interested here in finding climatologically representative noise statistics). On the other hand, propagation calculations based on the parabolic wave equation can handle varying atmospheric conditions and multiple reflections; ${ }^{35,36}$ we employ such a method ${ }^{37}$ in this work.

\section{Structure of this article}

The structure of this paper is as follows: first, we present our statistical model to represent turbine noise propagation via a probabilistic stability framework, including the necessary theory. Second, we introduce the computational flow model used to simulate an ensemble of atmospheric flow and temperature fields, including the dynamic effect of a turbine. Then, we introduce the parabolic-equation (PE) sound propagation model, with the turbine noise-source modeling; the latter includes both the physical representation and the inflow effect, as well as the simulated noise source. Subsequently, we show the results of aggregate modelling, including probability-weighted predictions of mean noise propagation both with and without vertical temperature gradients, as well as long-term predictions of variability. Finally, we discuss the results for the range of climates represented, within the context of common windfarm installations; this is followed by a summary of the current work's limitations and future tasks.

\section{THEORY AND MODELLING}

The basis for the acoustic propagation modelling is the parabolic equation (PE) method, with a 2-dimensional implementation and solver as outlined in the study by Barlas et al. ${ }^{38}$ This solver, which can also account for temperature-induced sound-speed profile deviations, ${ }^{39}$ is driven by 2-D wind fields generated for different atmospheric stability regimes by an atmospheric boundary-layer (ABL) flow model; the latter is the Reynolds-averaged Navier-Stokes (RANS) flow solver SCADIS. ${ }^{23}$

The mean flow is calculated including the wake effect, via an actuator disc implementation in SCADIS; this is done because the combined effect of atmospheric stability and the turbine wake on the flow is crucial in calculating the environmental propagation of turbine noise. The curvature of sound rays can be dominated by the mean wind profile $U(z)$ as affected by stability (caused by the surface heat flux), with the temperature profile $T(z)$ often playing a less direct role; this is elucidated later.

\section{A. Probabilistic model of atmospheric representation and propagation}

We aim to find meaningful turbine-noise propagation statistics, such as the mean and standard deviation of sound loss as a function of distance downwind. Thus, we begin by accounting for the statistical behavior of the primary variable characterizing the (aggregate) atmospheric 
effect on turbine-to-ground propagation: the Obukhov length. In particular, the inverse Obukhov length, defined by fluxes of heat $(H)$ and momentum $\left(u_{*}^{3}\right)$ in the surface layer $(\sim 10-30 \mathrm{~m}$ above ground), is a direct measure of the atmospheric stability

$$
L^{-1}=\kappa \frac{\frac{g}{T_{0}} H}{u_{*}^{3}},
$$

where $\kappa=0.4$ is the von Kármán constant, $g=9.8 \mathrm{~m} / \mathrm{s}^{2}$ is the acceleration due to gravity, and $T_{0}$ is the mean surface-layer air temperature. Further, its distribution $P\left(L^{-1}\right)$ tends to follow a universal form that is effectively scalable from site to site, as found by Kelly and Gryning, ${ }^{29}$ this form has been shown to predict the mean profile $U(z)$ at various sites. ${ }^{40}$ The wind profile dominates the sound speed profile, and so, the effect of stability on the sound speed profile is through the wind shear, particularly approaching receivers near ground; since we know the range of $L^{-1}$ values to be expected across (typical) turbine sites in practice, then knowing the form $P\left(L^{-1}\right)$ allows us to sample a number of $L^{-1}$ values and calculate the propagation for each situation. Specifically, we simulate the flow field-including turbine-induced wake-for a representative range of stability cases and calculate the propagation loss for each case, and then, we are able to compute a weighted sum of the case results based on the widths of the unstable $(L<0)$ and stable $(L>0)$ sides of the stability distribution.

The stability distribution for the Lille Valby (DK) site is shown in Fig. 1, calculated from two years of sonic-anemometer measurements taken at $10 \mathrm{~m}$ above ground. This is typical for mid-latitude $\operatorname{sites}^{29}$ and will be later used to represent climatological conditions for the RisøDTU turbine noise measurement campaign.

For our study, we selected 15 stabilities spanning the distribution shown in Fig. 1, including the neutral case of $L^{-1}=0 \mathrm{~m}^{-1}$. While Barlas et al. ${ }^{39}$ calculated propagation results for only a significantly stable and unstable case, here, we address the need to model the various propagation conditions over the range of stabilities. This is necessary because sound attenuation can be most significantly reduced for slightly to modestly stable cases, particularly at distances greater than $1 \mathrm{~km}$ from a turbine; i.e., the most stable cases do not cause the loudest signals at long distances. Less stable high-wind conditions, which occur more frequently, ${ }^{29}$ can enhance propagation, as can $\mathrm{ABL}$ depths that tend to occur in such conditions.

A basic probabilistic model is devised here, which allows estimation of low-order statistics of turbine noise propagation (and loss) due to varying flow conditions in the ABL. Most

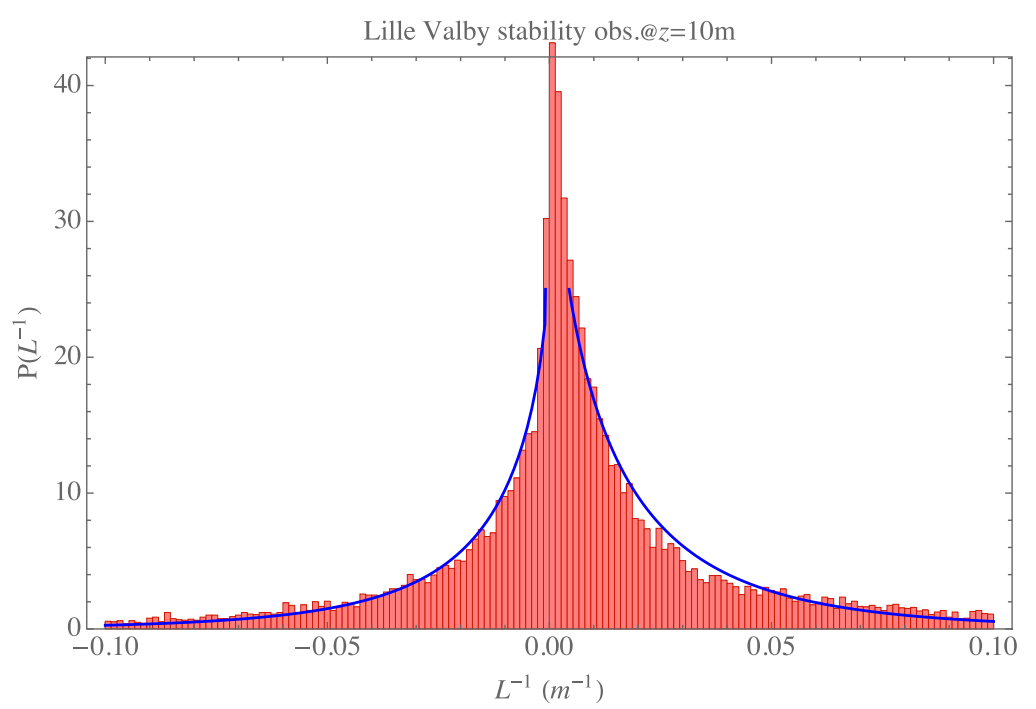

FIG. 1. Distribution of stability (inverse Obukhov length) for the Lille Valby site. Shaded/red: observations; the blue line is the "universal" stability distribution. ${ }^{29}$ Stable conditions occur when $L^{-1}>0$, unstable for negative $L^{-1}$. 
simply, the model calculates the weighted average of sound pressure loss (transmission loss, TL) by sampling over the relevant range of atmospheric stabilities, with the weights taken as the respective stability probabilities; this is analogous to-and follows from-the stabilityaffected weighted-mean wind profile model in the study by Kelly et al. ${ }^{29,40}$ Ideally, we have

$$
\mathrm{TL}(r, f)=\int \mathrm{TL}\left(r, f \mid L^{-1}\right) P\left(L^{-1}\right) d L^{-1}
$$

as a function of frequency $f$ and distance from source $r$, as well as height above ground $(z)$ and propagation angle from the mean wind direction $(\Delta \varphi)$; however, we do not yet consider the last two aspects and thus suppress them here in the notation. The integral is in practice approximated by a sum, sampling the stability distribution $P\left(L^{-1}\right)$; thus, it is written as a weighted average

$$
\mathrm{TL}(r, f)=\sum_{i} a_{i} \operatorname{TL}\left(r, f \mid L^{-1}\right) P\left(L_{i}^{-1}\right) .
$$

Here, $a_{i}$ is the weight for each case, proportional to the sampling interval in $L^{-1}$-space (or bin-width for each $L_{i}^{-1}$ ). The 2 -sided stability distribution is modelled $^{29,40}$ by

$$
P_{ \pm}\left(L^{-1}\right)=\frac{n_{+}}{\Gamma(5 / 2)} \frac{C_{ \pm}}{\sigma_{ \pm}} \exp \left[-\left(\left|L^{-1}\right| C_{ \pm} / \sigma_{ \pm}\right)^{2 / 3}\right],
$$

where " \pm " subscripts indicate the values for either stable $\left(L^{-1}>0\right)$ or unstable $\left(L^{-1}<0\right)$ conditions: $\sigma_{ \pm}=\left(g / T_{0}\right) \sqrt{\left\langle\left(H-\langle H\rangle_{ \pm}\right)^{2}\right\rangle_{ \pm}}\left\langle u_{* 0}\right\rangle_{ \pm}^{-3}$ is the variability in $L^{-1}, n_{ \pm}$is the fraction of occurrence and $\left\{C_{+}, C_{-}\right\}=\{1,3\}$ for stable/unstable conditions, respectively (see the study by Kelly and Gryning ${ }^{29}$ for more details). The widths $\left\{\sigma_{+}, \sigma_{-}\right\}$of the stability distribution for stable and unstable conditions and the fraction of stable conditions $\left(n_{+}=1-n_{-}\right)$determine the distribution $P\left(L^{-1}\right)$, and so for a given $\left\{\sigma_{+}, \sigma_{-}, n_{+}\right\}$, we can calculate $P\left(L^{-1}\right)$, from it $a_{i}$, and from a limited number of RANS and PE simulations.

We choose 15 stability cases, with $L_{i}^{-1}$ being sampled for simulation and analysis of $-12.3,-9.5,-7.7,-5,-3.5,-2.3,-1.6,0,9.7,12.7,19.2,23.2,32.1,46.5$, and $67.8 \mathrm{~km}^{-1}$. These $L_{i}^{-1}$ values span the range stabilities encountered $98 \%$ of the time on the stable side for Lille Valby; Fig. 1 confirms this. Priority is given to stable conditions (via the smaller sampling interval) because $L^{-1}$ has a greater effect on $U(z)$ and SPL in stable conditions; further, unstable conditions have an effect which does not vary much with $L^{-1}$ and saturates for more negative $L^{-1}$ (i.e., the atmosphere is well-mixed for any cases more unstable than the minimum value we chose). Again, for stabilities $L^{-1}<-0.01 \mathrm{~m}^{-1}$, the lower ABL is mixed enough to not give different propagation conditions; for $L^{-1}>0.04 \mathrm{~m}^{-1}$ (as shown later in this work), the attenuation does not increase, and there is also very little probability mass as seen in Fig. 1.

\section{B. Atmospheric boundary-layer flow model}

The SCADIS (SCAlar-DIStribution) flow model is a Reynolds-Averaged Navier-Stokes (RANS) solver employing a two-equation turbulence closure scheme, ${ }^{23}$ including a selfconsistent atmospheric stability formulation that gives results satisfying Monin-Obukhov theory. ${ }^{41}$ The code includes the effect of the Coriolis force as well as cloud cover (radiation), and reproduces both the diurnal cycle and the associated ABL depth variations. It was run in the 2$\mathrm{D}$ mode with a resolution of $10 \mathrm{~m}$, using the $k-\omega$ equations ${ }^{42}$ for turbulence closure. Diurnal cycles were run with various geostrophic winds $(G=\{8,10,12,14\} \mathrm{m} / \mathrm{s})$ in clear conditions, and $50 \%$ and $100 \%$ cloud cover conditions were also run for $G=10 \mathrm{~m} / \mathrm{s}$. In aggregate, 15 simulation cases were taken, which span the range of stabilities as mentioned in Sec. II A.

The turbine rotor is located at $x=0$ from heights $60 \mathrm{~m} \leq z \leq 140 \mathrm{~m}$ (virtual hub-height of $100 \mathrm{~m}$ ) above the ground level and is simulated using the common actuator disc method. The 

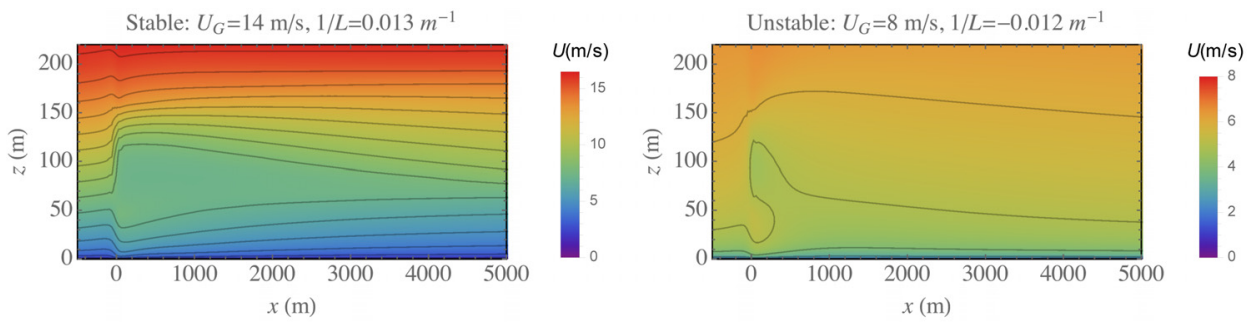

FIG. 2. Input wind fields for weakly stable and unstable regimes, produced by SCADIS. The turbine rotor (actuator disc) is located at $x=0, z=100 \pm 40 \mathrm{~m}$; contours drawn for integer values of $U$ (every $1 \mathrm{~m} / \mathrm{s}$ ).

effect of the wind turbine on airflow was prescribed via drag force distributed between 50 and $150 \mathrm{~m}$ above the ground. The force was also "smeared" over adjacent computational nodes in the horizontal direction, with three nodes used to smooth the horizontal pressure gradient like Troldborg et al. ${ }^{43}$ A uniformly distributed drag-coefficient $C_{d}=0.2$ was used in the central node of the canopy location and tapered symmetrically in the vertical around the hub height to account for the cross-sectional area in the cross-stream direction.

Two sample mean flow fields are shown in Fig. 2; the fields in the figure correspond to (top) mildly stable conditions with $L^{-1}=0.013 \mathrm{~m}^{-1}$ (i.e., higher wind speeds at turbine rotor heights) common during nights and winter, and (bottom) weakly unstable conditions with $L^{-1}=-0.012 \mathrm{~m}^{-1}$ commonly found during sunny or partly cloudy days. One can see that these are relatively common by noting that the values of $L^{-1}$ are near the peak region of $P\left(L^{-1}\right)$ shown in Fig. 1. The flow fields were generated using SCADIS for different geostrophic (driving) wind speeds, above a uniform rural/field roughness $\left(z_{0}=10 \mathrm{~cm}\right)$ and flat terrain. One can see the effect of stability on both the wind profile upwind of the turbine and the wake recovery, from Fig. 2. In the wake the stability affects the "competition" between recovering ambient high shear and turbulent mixing, and the distance over which these effects (and the flow) equilibrate.

Another stability-related aspect of the ABL that affects the flow and the propagation, which is implicitly incorporated in our probabilistic model (3) via SCADIS, is the ABL depth $h_{\mathrm{ABL}}$. In the cases shown in Fig. $2, h>250 \mathrm{~m}$, but for more stable conditions, the ABL can be shallower than $200 \mathrm{~m}$ (or even $100 \mathrm{~m}$ in more extreme cases). SCADIS captures the stabilityaffected depth by simulating the evolving ABL as well as cloud cover (which causes more neutral conditions and also affects $h_{\mathrm{ABL}}$ ). For example, the most stable case simulated $\left(L^{-1}=-0.012 \mathrm{~m}^{-1}\right)$ had a depth of $h_{\mathrm{ABL}} \approx 100 \mathrm{~m}$ and the associated mean "jet" spanning part of the rotor, resulting in negative shear in the wake of the rotor; the flow field from the rarest of simulated cases is shown in Fig. 3. Situations like the stable shallow-ABL case shown in Fig. 3 can lead to ducting and enhanced long-range propagation or increased attenuation, depending on the ABL depth and the terrain; in fact, the latter is more likely for the case in the figure, as shown in Sec. III.

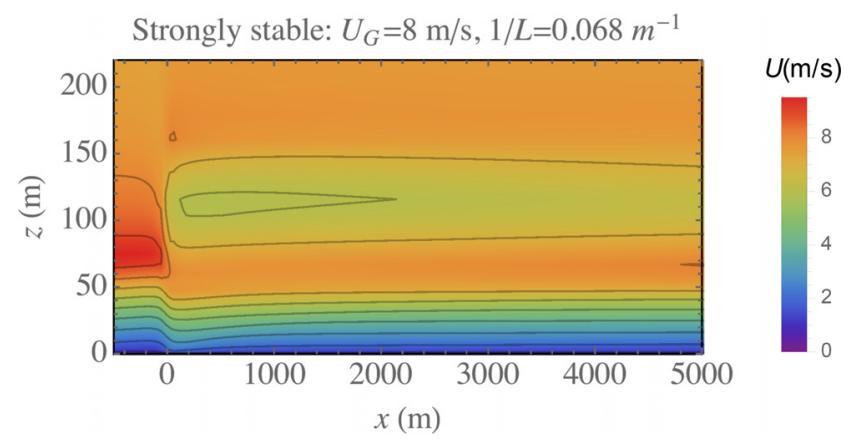

FIG. 3. Input wind fields for the most stable (rarest) sample/case simulated by SCADIS. (Contours drawn for integer values of $U$, as shown in Fig. 2.). 


\section{Sound propagation model}

For propagation modelling, DTU's WindSTAR-PRO (Wind turbine Simulation Tool for AeRodynamic Noise PROpagation) $)^{38,39}$ was used. The tool includes several parallelized implementations of Parabolic Equation (PE) models, solved per frequency and realization. In this study, a two-dimensional wide-angle PE method ${ }^{35}$ is employed, where the moving atmosphere is replaced by a hypothetical motionless medium having an effective speed of sound $c_{\text {eff }}$ that accounts for refraction due to wind speed gradients: $c_{\text {eff }}(x, z)=c(x, z)+V_{p}(x, z)$, where $V_{p}$ is the component of mean wind velocity along the direction of propagation between the source and the receiver and $c$ is the speed of sound calculated via $c=\sqrt{\gamma R T}$, where $\gamma$ is the specific heat ratio, $R$ is the gas constant, and $T$ is the temperature (obtained from the flow solver, also see Sec. II B). The spatial resolution in both directions is set to one eighth of the wavelength ( $\Delta x=\Delta z=\lambda / 8$; where $\lambda$ is the wavelength of the considered frequency). Only the flat terrain is considered and the ground impedance is characterized using the four-parameter model developed by Attenborough ${ }^{44,45}$ with an effective flow resistivity of $200 \mathrm{kPa} \mathrm{m}^{-2} \mathrm{~s}$ representative for grassland. The other parameters of the impedance model are kept constant: pore shape factor $\left(s_{p}=0.75\right)$, Prandtl number $\left(N_{P r}=0.72\right)$, grain shape factor $\left(n^{\prime}=0.5\right)$, porosity $(\Omega=0.3)$, and ratio of specific heats $(\gamma=1.4)$ and density $\left(\rho=1.19 \mathrm{~kg} / \mathrm{m}^{3}\right)$. All simulations are carried out for $\frac{1}{3}$-octave band centre frequencies from $20 \mathrm{~Hz}$ to $800 \mathrm{~Hz}$, and the corresponding sound pressure levels are summed logarithmically to obtain the overall SPL

$$
\mathrm{SPL}_{\text {tot }}=10 \log _{10}\left(\sum_{i=1}^{N} 10^{\operatorname{SPL}\left(f_{i}\right) / 10}\right),
$$

where $N$ is the number of frequencies used. The sound pressure level $\operatorname{SPL}\left(f_{i}\right)$ is defined as

$$
\operatorname{SPL}\left(f_{i}, r\right)=L_{W}\left(f_{i}\right)-10 \log _{10}\left(4 \pi r^{2}\right)-r \alpha\left(f_{i}\right)+\operatorname{TL}\left(f_{i}, r\right),
$$

where the first three terms on the right-hand side represent the source power level, geometrical spreading, and atmospheric absorption, respectively. The absorption coefficient is calculated according to ISO $9613-2^{30}$ for air at $20^{\circ} \mathrm{C}$ with a relative humidity of $80 \% .^{46}$ The last term represents the transmission "loss": the deviation from the free field of a source due to ground effects, atmospheric refraction, turbulence, etc.; the last term is calculated using the PE method.

\section{Source modelling: Inflow and physical representation}

Wind turbines are three-dimensional, complex noise sources, considering the rotation of the blades and the unsteady flow field around them. Recently, a coupled wind turbine noise generation-propagation model was proposed in the study by Barlas et al., ${ }^{37}$ where the source is represented in a three-dimensional and unsteady manner within the PE solver. In this study, our focus is on the mean sound pressure levels downwind of the turbine, and so, we use a mean two-dimensional approach, i.e., with a simplified source representation. Before all the
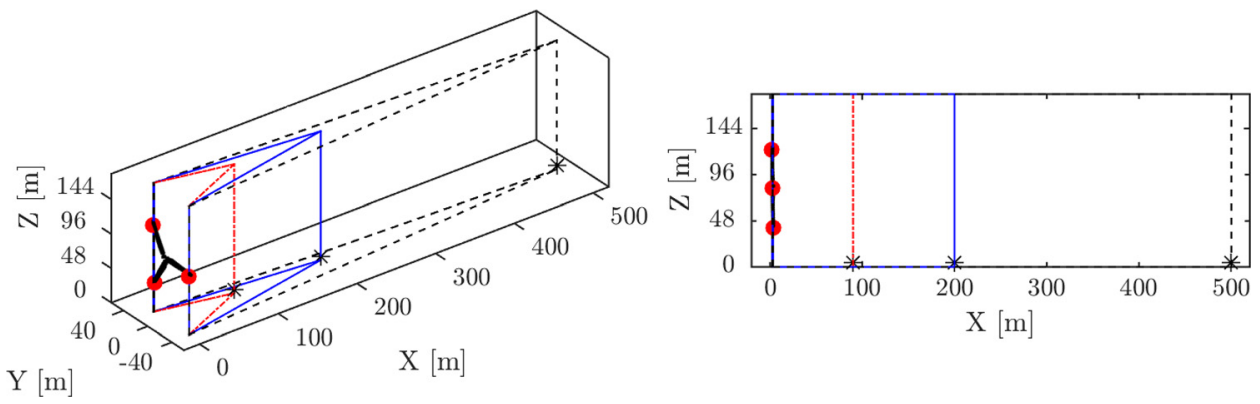

FIG. 4. Source representation within the propagation model. Left: Three dimensional and unsteady approach. Right: Twodimensional and steady approach. 

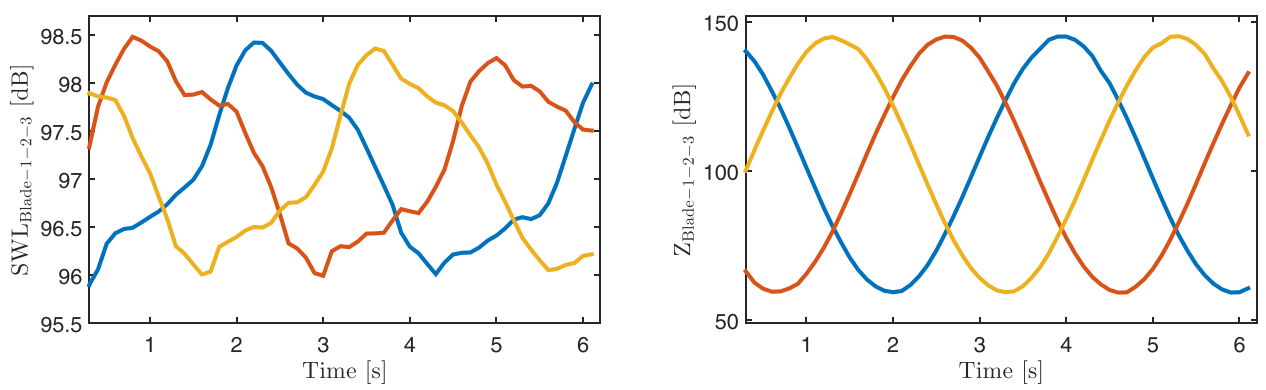

FIG. 5. Time-varying source power level (left) and vertical location (right) of each blade, for 3D-WUS-UF (each source within the PE model).

simulations were carried out for this study, mean integrated sound pressure levels obtained from the various techniques are compared, in order to justify our simplified choice; these techniques are described below.

-3D Weighted Unsteady Source + Unsteady LES Flow (3D-WUS-UF):

At each time step, a two-dimensional PE domain is constructed from each blade's noisiest element to each receiver location, while the source coordinates remain three-dimensional (see Fig. 4). The background flow field is obtained using large-eddy simulation (LES) and interpolated and updated at each time step for each 2D PE domain. The source levels are obtained from the aero-elastically coupled wind turbine noise generation model. ${ }^{38}$ The propagation simulations are carried out for a 10 -min duration, with a time step of $0.1 \mathrm{~s}$. This method is taken as the reference, to which the following three methods' results are compared. Figure 5 shows the time-variation of the source power level and height for this technique.

- 3D Weighted Unsteady Source + Mean LES Flow (3D-WUS-MF):

Source representation and weighting of the source levels are identical with the previous technique, but only the time-averaged LES flow field is used as input.

- 2D Weighted Unsteady Source + Mean LES Flow (2D-WUS-MF):

The lateral $(y-)$ coordinate of each source is set to 0 , i.e., the 2D PE domain lies in the $x$-z plane (Fig. 4). The source levels from the unsteady 3-d (3D-WUS-UF) method are used, and simulations are carried out for one full revolution.

- 2D Unweighted Unsteady Source + Mean LES Flow (2D-MUS-MF):

The source coordinates are identical to the 2D-WUS-MF technique, but time-averaged source levels are used for all sources and all times.

Figure 6 shows the error ensuing from the use of the various source-modelling approaches, relative to the time-varying 3D-WUS-UF PE simulations. Here, "error" is described as the time-averaged overall SPL difference between the aforementioned source representation techniques at each receiver location. It is seen that the error in the mean $2 \mathrm{D}$ source representation basically follows the same pattern as the 2D unsteady source method; both vary a small amount $(\lessgtr 0.8 \mathrm{dBA})$ with the distance. The relatively small error-and yet smaller variation in error-
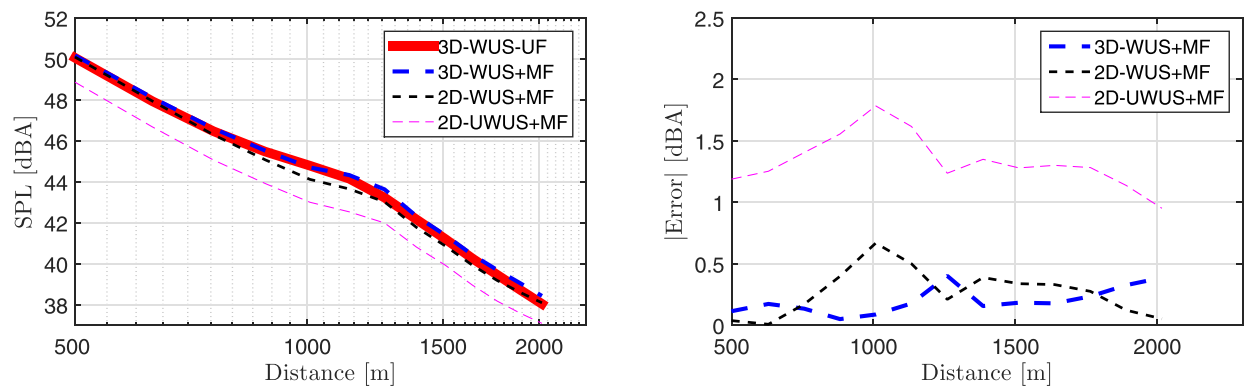

FIG. 6. Left: Sound pressure level versus distance for different source and flow field representations. Right: Error due to the simplifications of the source and flow field representations. 


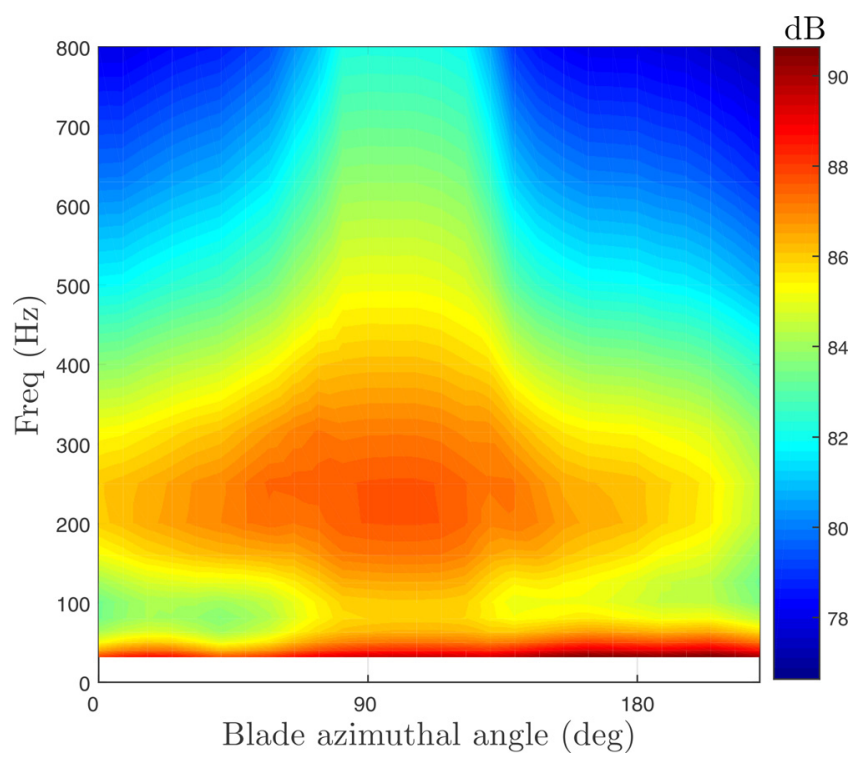

FIG. 7. Single source power level distribution with respect to the blade azimuthal angle.

incurred when using a mean 2D source formulation allows the error to simply be modelled as a bias. The focus of this study is the mean propagation per atmospheric condition based on stability, rather than detailed unsteady representation. Thus, the mean 2D source representation is used here, with acknowledgement of the underestimation of SPL indicated in Fig. 6.

\section{Turbine noise source}

The PE solver calculates the frequency-dependent propagation, given a source spectrum; more details can be found in the study by Barlas et al. ${ }^{38,39}$ The turbine noise source was modelled using the 2D weighted unsteady source technique described in Sec. IIC 1. The simulations were carried out for one full rotation. Subsequently, the sound pressure levels were averaged. The frequency-dependent source power level $L_{W}\left(f_{i}\right)$ is shown in Fig. 7. This plot shows the variation of the frequency-dependent source power level of a single blade with respect to its azimuthal angle (with $0^{\circ}$ corresponding to the rotor top). The distribution shows a peak around 120 degrees blade location, which is in agreement with the experimental source identification studies that are carried out by Oerlemans $e t a l .{ }^{47}$ The total propagation result per frequency $f_{i}$ for distance $r$ downwind from the source is found via Eq. (6).

\section{RESULTS AND DISCUSSION}

The sound pressure levels found via the PE propagation code and Eqs. (3)-(6), where the PE calculation has not (yet) included $d T / d z$, are shown in Fig. 8 for all cases considered. The results are plotted as a function of distance, for a receiver height of $2 \mathrm{~m}$ above ground. In addition to the different stability cases (colored lines), Fig. 8 shows the total result (solid black line) calculated using all the cases with the probabilistic model (6) using the Lille Valby values for the stability distribution (corresponding to Fig. 1).

The stable cases contribute most to elevating the sound pressure level at longer distances due to (wake-affected) shear-induced refraction. Figure 9 shows the stable cases together, indicating the stability for each case; in addition to the total weighted mean (solid black as in Fig. 8), the figure also displays the weighted mean SPL for the stable cases only (dotted black).

From Fig. 9, one can see that the most stable cases lead to noise reduction, also due to the shallow ABL depth accompanying them in the modeled flow field. From the light-blue and brown lines $\left(L^{-1}\right.$ of 0.046 and $\left.0.068 \mathrm{~m}^{-1}\right)$, one sees that these most stable cases, with ABL 


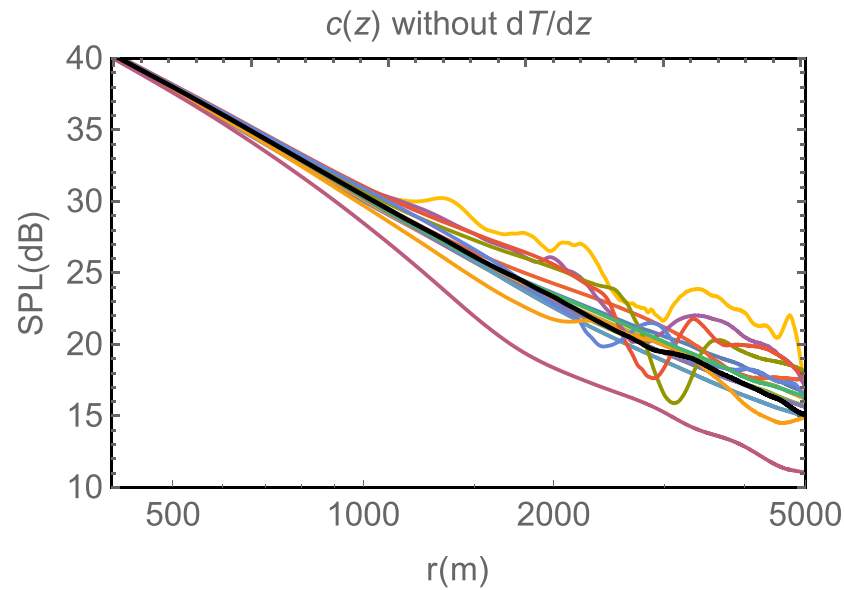

FIG. 8. Total SPL for all cases (colored lines), ignoring $d T / d z$ within $c(z)$; the solid black line is the probability-weighted mean.

depths and associated jets occurring below the rotor top (as seen in Fig. 3), give the lowest sound levels. Cases with modest stability, which are accompanied by ABL depths greater than twice the rotor top height in the RANS simulations, show the loudest levels at long distances.

In the analysis and results thus far, we have not included the effects of the temperature profile. Although SCADIS provides $T(z)$, the vertical variation of $T$ was not initially used in the effective sound speed profile $c_{\text {eff }}(z)$ for the PE solver because the wind speed profile-notably the shear, $d U / d z$ - contributes much more to $c_{\text {eff }}(z)$. But for very stable cases with a shallow $\mathrm{ABL}$, the temperature may have a significant effect. Indeed, incorporating the temperature profile into $c_{\text {eff }}(z)$ changes the results for such cases, as evinced in Fig. 10. The figure shows results including the effect of $T(z)$. One can see in Fig. 10 that the weakly stable case, which has the least transmission loss (i.e., loudest noise, orange lines), is not affected much by inclusion of the temperature profile; however, the most stable cases are significantly impacted by accounting for $T(z)$ in $c_{\text {eff }}(z)$, with an increase of several dB in SPL for distances beyond $1 \mathrm{~km}$. Thus, inclusion of $\partial T / \partial z$ for very stable cases increases the long-range SPL predictions although the weighted mean (dotted black line for stable cases and black for all cases in Fig. 10) changes modestly because increasingly stable cases occur with decreasing frequency. However, we note that the SPL for stable cases is still higher than in unstable cases.

To further demonstrate the utility of the probabilistic method, as driven by a strategically sampled set of PE and RANS simulations, Fig. 11 displays the total SPL for different

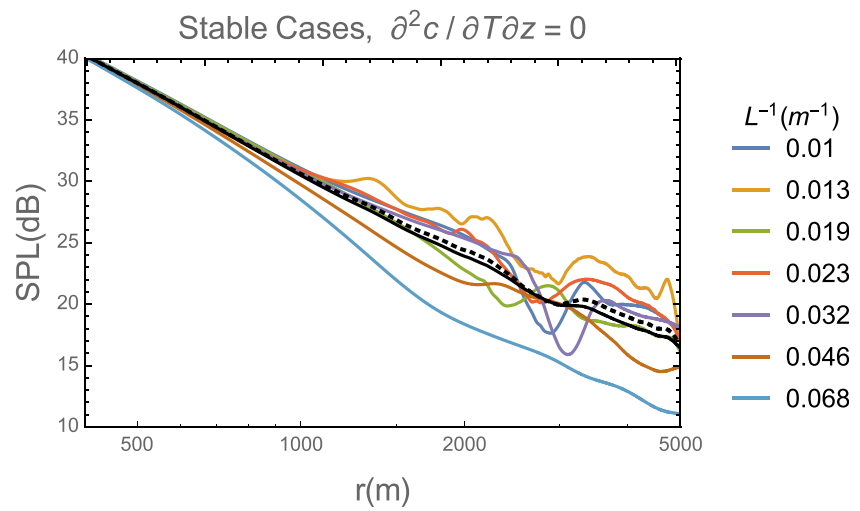

FIG. 9. Total SPL ignoring $d T / d z$ within $c(z)$, as in Fig. 7, but for stable cases; also, probability-weighted mean for all (solid black) and for all stable (dotted black) cases. 


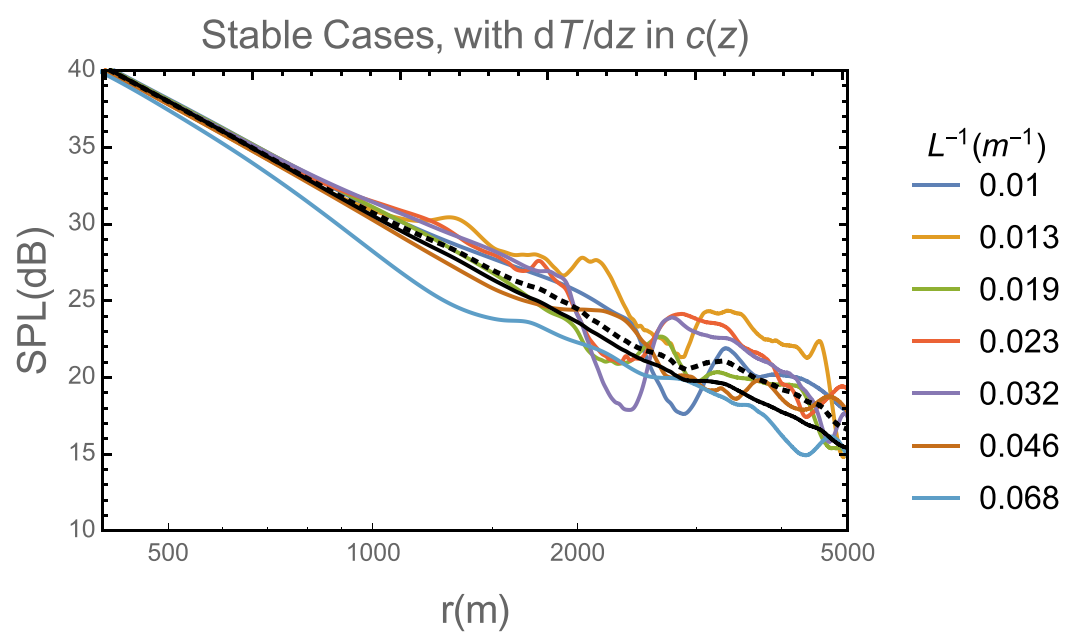

FIG. 10. SPL including $T(z)$ within $c(z)$; probability-weighted mean for all (solid black) and for all stable (dotted black) cases.

representative climates, calculated using (3); the bottom plot in the figure also displays the integrated SPL for each respective climate minus the neutral climate's integrated SPL, as a function of distance downwind, i.e., the overall change compared to having no surface-induced stability effects. The climates are the typical mid-latitude/temperate case (Lille Valby) considered above; very unstable climate (Basel, Switzerland) and stabler conditions (Cabauw, NL) found by Kelly and Gryning, ${ }^{29}$ a neutral climate; and a very stable climate. The stability distribution $P\left(L^{-1}\right)$ and consequent simulation-case weights $a_{i}$ corresponding to the first three were found based on the measured $\left\{n_{+}, \sigma_{+}, \sigma_{-}\right\}$from each site; then, the weighted average of all cases was calculated for each site via (3). The "very stable" climate has $\left\{n_{+}, \sigma_{+}, \sigma_{-}\right\}$equal to $\left\{0.86,0.06 \mathrm{~m}^{-1}, 0.02 \mathrm{~m}^{-1}\right\}$, while the neutral-dominated case has $\left\{n_{+}, \sigma_{+}, \sigma_{-}\right\}=\left\{0.5,0.03 \mathrm{~m}^{-1}, 0.01 \mathrm{~m}^{-1}\right\}$.

From Fig. 11, one can see that overall, there does not appear to be a large difference in SPL, when stability-affected propagation results are aggregated (in effect, averaged with weights) according to the distribution of stability conditions at typical sites: there is less than $1 \mathrm{~dB}$ difference between the modestly stable (Cabauw), typical (Lille Valby), and neutral cases. This is not completely surprising since neutral conditions dominate the stability distribution at such sites. The unstable/convectively dominated Basel site results do show up to $2 \mathrm{~dB}$ lower SPL, which could likely be reduced yet further if turbulent scattering were also included. ${ }^{5,14}$ The very stable climate shows increasing SPL relative to neutral conditions for distances from $\sim 1$ to $2 \mathrm{~km}$, with levels more than $1 \mathrm{~dB}$ louder at $\sim 3-4.5 \mathrm{~km}$ downwind. The figure further indicates that over distances up to $\sim 1 \mathrm{~km}$, the propagation (which also includes atmospheric absorption and geometrical spreading) is roughly approximated by $r^{-2.55}\left(\sim r^{-18 / 7}\right.$, dotted line $)$. However, for distances beyond $\sim 20 z_{\text {hub }}$, the modeled long-term mean SPL downwind has a distance-dependence more like $r^{-2}$ (dot-dashed line), i.e., wake, stability, and ground effects roughly cancel the effect of atmospheric absorption, when summed over audible frequencies.

To show the expected long-term variability in SPL for each case (climate), Fig. 12 displays the $P\left(L^{-1}\right)$-weighted variance, i.e., the probability-weighted integral of the square of the SPL difference from the climate-mean, as a function of distance downwind. One can see the effect of stability on the variability, considering the weighted-variances of SPL plotted in Fig. 12; the "neutral" climate is again defined above as having a very narrow distribution, and for a purely neutral climate, the relative SPL variability $\sigma_{S P L}$ would be 0 . Figure 12 also shows that for very stable climates, the variability is slightly higher than that for more typical climates dominated by stable conditions, at least for distances downwind up to roughly $3 \mathrm{~km}$. Beyond that distance downwind, something potentially counter-intuitive happens: the more modestly stable distributions (more typical climates) show higher $\sigma_{\mathrm{SPL}}$ for $r$ from $\sim 3 \mathrm{~km}$ to $5 \mathrm{~km}$. These variances are equivalent to rms SPL deviation amplitudes that grow from roughly $1 \mathrm{~dB}$ to $2.5 \mathrm{~dB}$ as 

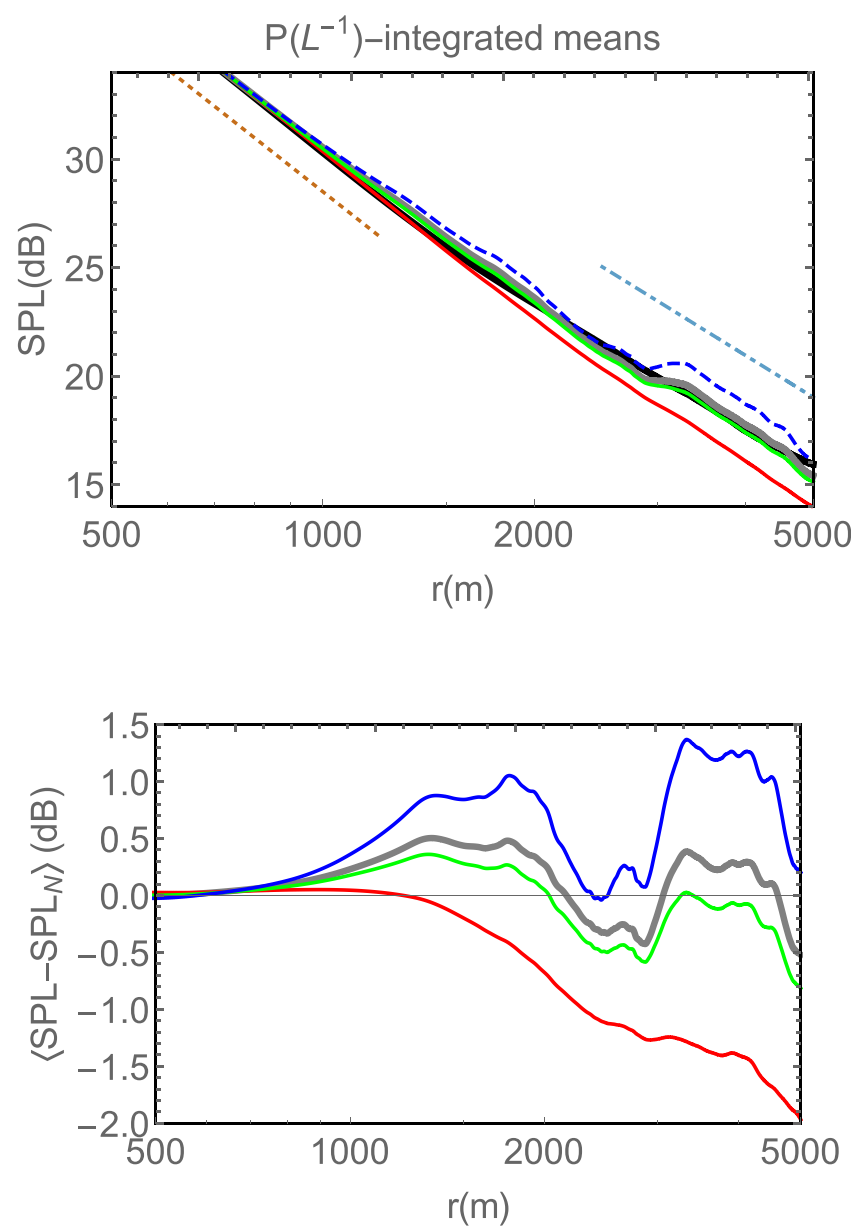

FIG. 11. Top: Overall (stability-integrated) mean SPL for different climates; bottom: difference between the overall SPL and the neutral result. Black (top): neutral climate; gray/thick: typical mid-latitude (Lille Valby, as in Figs. 9 and 10); green: modestly stable climate (Cabauw); red: unstable climate (Basel); blue: very stable climate.

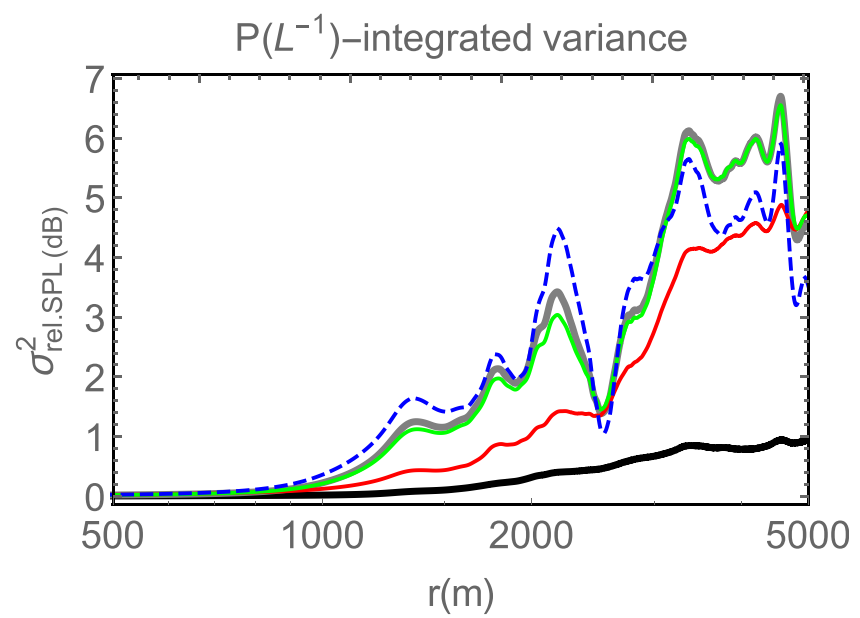

FIG. 12. Stability-integrated variance of SPL relative to the respective mean for different climates, as a function of distance downwind. Black: neutral climate; gray/thick: typical mid-latitude (Lille Valby, as in Figs. 9 and 10); green: modestly stable climate (Cabauw); red: unstable climate (Basel); blue: very stable climate. 
one considers distances that increase from $\sim 1.3 \mathrm{~km}$ to $4.5 \mathrm{~km}$ downwind. The distribution dominated by unstable conditions (Basel site) shows less variability, but this is partly due to our propagation model not including turbulent scattering.

\section{A. Regarding downwind propagation and stability}

The results shown in Figs. 9-12 are also supported by theory, which can also give a guide to inclusion or exclusion of vertical temperature gradients in the acoustic modelling. Considering downwind propagation, the effective speed of sound (including the wind speed) ${ }^{48}$ has a vertical derivative

$$
\frac{d c_{\mathrm{eff}}}{d z}=\frac{\partial c}{\partial T} \frac{\partial T}{\partial z}+\frac{\partial c_{\mathrm{eff}}}{\partial V_{p}} \frac{\partial V_{p}}{\partial z}=\frac{\partial U}{\partial z}\left[\cos \left(\varphi_{p}-\varphi_{U}\right)+\frac{c}{2 T_{0}} \frac{\partial T / \partial z}{\partial U / \partial z}\right]
$$

where $c(z)=\sqrt{\gamma R T(z)}$ is the temperature-dependent speed of sound, $\gamma$ is the specific heat ratio, $R$ is the gas constant, $V_{p}$ is the component of mean wind velocity along the direction of propagation, $U$ is the mean wind speed, and $\varphi_{p}-\varphi_{U}$ is the angle between the direction of propagation and mean wind. For propagation directly downwind from a wind turbine, $\cos \left(\varphi_{p}-\varphi_{U}\right)=1$; since in the ABL, one may invoke similarity to write $\partial U / \partial z=\left(u_{*} / \kappa z\right) \Phi_{m}(z / L)$ and $\partial T / \partial z$ $=\left(\theta_{*} / \kappa z\right) \Phi_{h}(z / L)$, then

$$
\left.\frac{d c_{\mathrm{eff}}}{d z}\right|_{\varphi_{p}=\varphi_{U}} \simeq \frac{\partial U}{\partial z}\left[1+\frac{c}{2 u_{*}} \frac{\theta_{*}}{T_{0}} \frac{\Phi_{h}(z / L)}{\Phi_{m}(z / L)}\right] \sim \frac{\partial U}{\partial z}\left[1+\frac{c u_{*}}{g L}\right]
$$

because $\Phi_{h}$ and $\Phi_{m}$ do not differ much (see, e.g., the study by Businger et al. ${ }^{49}$ )—particularly for the stability range considered. Then, one sees in (8) that for $L^{-1} \ll g / c u_{*}$, we can ignore the $\partial T / \partial z$ contribution to $d c_{\text {eff }} / d z$. For most stability distributions, such as those we have treated, we see that the tails of $P\left(L^{-1}\right)$ are at $L^{-1}$ which do not allow such ignorance of $\partial T / \partial z$ - as evidenced by the difference between the results in Fig. 9 (calculated without $d T / d z$ in $c_{\text {eff }}$ ) and Fig. 10 (calculated including $d T / d z$ ). From (7), one may also note that $\partial T / \partial z$ becomes more relevant for propagation directions differing more from the mean wind direction; i.e., for $L^{-1}$ not negligible compared to $\sim g \cos \left(\varphi_{p}-\varphi_{U}\right) /\left(c u_{*}\right)$, temperature effects can matter. Climatologically, this means that for directions deviating from downwind, then temperature gradients, e.g., the inversion at the ABL top, become more important.

\section{SUMMARY AND CONCLUSION}

In this work, a probabilistic model for propagation conditions was developed, facilitating the prediction of long-term (multi-year) wind turbine noise propagation statistics downwind. A universal analytical form of the probability density function of surface-layer stability $P\left(L^{-1}\right)$ over land ${ }^{29}$ (where $L$ is the Obukhov length), which depends on three parameters calculable from long-term meteorological (sonic anemometer) measurements, allows the calculation of frequency-weighted statistics representative of yearly atmospheric conditions for a given site (ultimately over a turbine lifetime). Based on the form of the stability distribution and the range of stability conditions possible for turbine sites, an ensemble of stability conditions, i.e., atmospheric classes, were made; a corresponding set of simulations were carried out using the atmospheric RANS solver SCADIS. For each class, the simulation has a different mean wind speed and surface heat flux (thus stability), as well as corresponding ABL depth via the solution. The flow field for each simulation was used as input to drive the PE acoustic propagation model, which gave distance-dependent results for each atmospheric class. Noise propagation statistics were obtained using statistical weights according to the stability distribution, for a number of climates spanning conditions expected at wind farm sites.

Predicted noise levels were highest for modestly stable conditions, which occur during winter and nighttime in mid-latitude climates, while modelled SPL was also elevated for very 
stable (rarer) conditions. The latter is due to the reduced depth of the ABL with increasing near-surface stability and the turbine wake. The effect of the ABL-capping temperature inversion on sound refraction via both the wind shear and the temperature gradient is crucial and captured via the flow model-which also accounts for the variation of the ABL depth with surface stability. We again note the role of the temperature gradient (including its value within the ABL-capping "inversion") in the sound propagation calculations, especially for stable climates; herein, we have also introduced a basic scaling analysis to gauge the importance of $d T / d z$ relative to $d U / d z$ in the propagation.

For the unstable-dominated climate (Basel, heat-island), the $P\left(L^{-1}\right)$-weighted mean SPL was lower than the neutral SPL, with the difference (SPL $-S_{S P L}$ neutral) increasing with the distance downwind for $r \gtrsim 1 \mathrm{~km}$; the difference grew to $-2 \mathrm{~dB}$ at a distance of $5 \mathrm{~km}$ for this case. For typical (non-tropical) turbine sites dominated more by stable conditions (due to buoyancy affecting wind shear more in stable conditions than in unstable conditions ${ }^{25,29}$ ), the mean SPL was a bit higher $\left(\sim \frac{1}{2} \mathrm{~dB}\right)$ than in absolute neutral conditions for distances of $\sim 1-2 \mathrm{~km}$ and $\sim 3-4.5 \mathrm{~km}$, but similar to or less than the neutral result at $\sim 2-3 \mathrm{~km}$ and $\sim 4.5-5 \mathrm{~km}$ downwind. For an extremely stably dominated climate, i.e., with a relatively long tail on the stable side of the $1 / L$ distribution (such as what could be found in some climates with harsh winters and/or typically clear nights much colder than daytime), a more significant relative increase in the noise level is found beyond $\sim 1 \mathrm{~km}$ downwind - with (SPL $-\mathrm{SPL}_{\text {neutral }}$ ) approaching $1.5 \mathrm{~dB}$ for the stability statistics outlined in Sec. II A for this stability distribution.

While the mean SPL differences (relative to neutral conditions) may seem to be relatively small, the variability of SPL is significantly larger, especially for typical climates. The probability-weighted variability $\sigma_{\mathrm{SPL}}$ generally increases with the distance. For $r \gtrsim 3 \mathrm{~km}$ downwind, $\sigma_{\mathrm{SPL}}$ is highest for stability distributions commonly found in mid-latitudes (modestly dominated by stable conditions, e.g., Lille Valby and Cabauw shown above) between 2 and $3 \mathrm{~dB}$ in that range. We point out that such variability can be significant, given that the overall levels predicted at distances beyond $\sim 3 \mathrm{~km}$ are $\sim 15-20 \mathrm{~dB}$-not far from the audibility threshold of the human hearing considering the effect of, e.g., sleeping indoors with open windows.

\section{A. Discussion and outlook}

As is the case with all modelling, the methodology that we developed and employed in this work involved some simplifying assumptions. The aim was to show the long-term mean and variance of turbine noise levels, as affected by the interacting wake and ABL including buoyancy. This begins with the assumption that surface-layer stability (reciprocal Obukhov length $L^{-1}$ ) can be used to build an ensemble of members which together represent the propagation conditions. Thus, we effectively reduce the joint-distribution of near-surface friction velocity $\left(u_{*}\right)$ and surface heat flux, collapsing such into $P\left(L^{-1}\right)$; such an assumption becomes tenuous, e.g., offshore or across lakes. ${ }^{40}$ We have also relied on $P\left(L^{-1}\right)$, with a limited range of temperatures $\left(16^{\circ}-30^{\circ}\right)$ in the simulated $\mathrm{ABL}$, because the temperature dependence of absorption only had a weak effect $\left(<0.3 \mathrm{~dB}\right.$ change per $20^{\circ}$ temperature difference) due to the dominance of low frequencies in the noise. As shown by (7) and (8), $d T / d z$ and $d U / d z$ dominate the longrange propagation paths; they are in turned influenced primarily by $L^{-1}$ and the turbine wake. The mean temperature contribution to $d c_{\text {eff }} / d z$ is relatively small compared to the shear $d U / d z$, as discussed in the text following (8); this contribution does have a temperature dependence seen in (7) behaving as $c / T_{0} \propto T^{-1 / 2}$, which can increase an additional $\sim 4 \%$ for mean temperatures dropping several degrees below freezing. Thus, our use of limited temperature range and $P\left(L^{-1}\right)$ is representative of conditions expected at mid-latitude sites encountered. ${ }^{50}$

We have also used the ABL depths simulated by SCADIS based on each representative condition's surface heat flux (and cloudiness) and (geostrophic) wind speed, with a predefined value of the "free-atmosphere" temperature gradient above the ABL; to expand our analysis to be more complete, we wish to repeat the modelling for different values of $d T / d z$ in the capping-inversion (free-atmosphere). Further, we have only used a single ABL depth $\left(z_{i}\right)$ per surface-stability; expanding the ensemble to include multiple $z_{i}$ for each $1 / L$, e.g., via the 
distribution ${ }^{51}$ of $z_{i}$ (such as was characterized by Liu and Liang ${ }^{28}$ ), could improve our statistical model's representativity. The boundary-layer depth evolves with the heat flux per time of day as simulated in SCADIS, but this can be expanded (e.g., per initial temperature profile and cloudiness). The latter two enhancements can be used to extend the model through determination and refinement of their joint distribution with the surface-based stability, i.e., $P\left(L^{-1},\left.\frac{d T}{d z}\right|_{\text {inv }}, z_{i}\right)$; this is an ongoing subject in boundary-layer meteorology. ${ }^{52}$ Further, such joint distributions are also at the heart of statistical characterization of extreme annoyance events, which is very relevant to planning and operation of wind farms.

Also note that the turbine representation (actuator disc) within the RANS flow-solver could be refined; here, we began with a basic implementation which reproduces the key spatially- and stability-dependent flow features such as the wake, its decay, and associated mean gradients $\{d U /$ $d z, d T / d z\}$. A more sophisticated thrust-coefficient (and thus drag) description could be attempted, and, e.g., the wake-decay and its sensitivity to parameterization could be investigated.

We note that the use of the 2D mean-flow source function involves another assumption, in effect, that stability and associated wind shear do not appreciably affect the "bias" incurred relative to use of a 3D source with unsteady inflow. As shown in Sec. IIC 1 and Fig. 6, this bias (mean error) is less than $0.5 \mathrm{~dB}$ at a $2 \mathrm{~km}$ distance downwind, diminishing to $\sim 0.1 \mathrm{~dB}$ at $5 \mathrm{~km}$ downwind; thus the stability-affected bias is not likely to be significant but could be explored. We have thus far treated only downwind propagation from a single turbine, due to turbine noise generally being loudest downwind, with the simplification to two dimensions for modelling of the flow and source function. Future research includes propagation in other directions, as well as multiple sources and subsequent wakes, in three dimensions.

In this work, we have presented unweighted SPL, integrated over frequency, in order to show overall noise statistics. Further frequency-dependent analysis, particularly over different surfaces and for a larger number of cases (the latter mentioned in the paragraphs above), is a subject of future work; this is relevant, e.g., for domicile interaction and indoor noise (such as rattling windows) as well as supporting investigation of noise modulation.

\section{ACKNOWLEDGMENTS}

M.K. is thankful for internal support from DTU (2016 Wind Energy departmental cross-cutting activity on turbine noise) for this work.

${ }^{1}$ B. Gutenberg, "Propagation of sound waves in the atmosphere," J. Acoust. Soc. Am. 14, 151-155 (1942).

${ }^{2} \mathrm{U}$. Ingård, "A review of the influence of meteorological conditions on sound propagation," J. Acoust. Soc. Am. 25, 405-411 (1953).

${ }^{3}$ A. Kriebel, "Refraction and attenuation of sound by wind and temperature profiles ovr a ground plane," J. Acoust. Soc. Am. 51, 19-23 (1972).

${ }^{4}$ T. Embleton, G. Thiessen, and J. Piercy, "Propagation in an inversion and reflection at the ground," J. Acoust. Soc. Am. 59, 278-282 (1976).

${ }^{5}$ J. E. Piercy, T. F. W. Embleton, and L. C. Sutherland, "Review of noise propagation in the atmosphere," J. Acoust. Soc. Am. 61, 1403-1418 (1977).

${ }^{6} \mathrm{~A}$. Ziemann, K. Balogh, and K. Arnold, "Modelling and measuring the atmospheric excess attenuation over flat terrain during night time conditions," Meteorol. Z. 16, 429-441 (2007).

${ }^{7}$ K. Bolin, M. Boué, and I. Karasalo, "Long range sound propagation over a sea surface," J. Acoust. Soc. Am. 126, 2191-2197 (2009).

${ }^{8}$ D. Heimann, "Wide-area assessment of topographical and meteorological effects on sound propagation by time-domain modeling," J. Acoust. Soc. Am. 133, EL419-EL425 (2013).

${ }^{9} \mathrm{~W}$. Wilken, "Experimental study of the influence of varying atmospheric conditions on sound propagation close to the ground," Acustica 62, 55-65 (1986).

${ }^{10} \mathrm{O}$. Öhlund and C. Larsson, "Meteorological effects on wind turbine sound propagation," Appl. Acoust. 89, 34-41 (2015).

${ }^{11} \mathrm{~A}$. Bigot, C. Mirabel, and P. Dutilleux, "Influence of vertical temperature gradient on backround noise and on long-range noise propagation from wind turbines," Proceedings of the International Congress on Sound and Vibration (2016).

${ }^{12}$ J. Forssén, M. Schiff, E. Pedersen, and K. P. Waye, "Wind turbine noise propagation over flat ground: Measurements and predictions," Acta Acust. Acust. 96, 753-760 (2010).

${ }^{13}$ M. Stigwood, S. Large, and D. Stigwood, "Cotton farm wind farm-long term community noise monitoring project-2 years on," in 6th International Meeting on Wind Turbine Noise (2015).

${ }^{14}$ T. F. W. Embleton, “Tutorial on sound propagation outdoors,” J. Acoust. Soc. Am. 100, 31-48 (1996).

${ }^{15}$ E. Salomons, Computational Atmospheric Acoustics (Kluwer Academic Publishers, 2001), p. 335.

${ }^{16}$ J. C. Wyngaard, Turbulence in the Atmosphere (Cambridge University Press, 2010), p. 393. 
${ }^{17}$ D. H. Lenschow, J. Mann, and L. Kristensen, "How long is long enough when measuring fluxes and other turbulence statistics?," J. Atmos. Ocean Technol. 11, 661-673 (1994).

${ }^{18}$ S. Lee, D. Lee, and S. Honhoff, "Prediction of far-field wind turbine noise propagation with parabolic equation," J. Acoust. Soc. Am. 140, 767-778 (2016).

${ }^{19}$ A. Sogachev, "A note on two-equation closure modeling of canopy flow," Boundary-Layer Meteorol. 130, 423-435 (2009).

${ }^{20} \mathrm{D}$. Sharpe, "A general momentum theory applied to an energy-extracting actuator disc," Wind Energy 7, 177-188 (2004).

${ }^{21}$ N. Troldborg, F. Zahle, P.-E. Réthoré, and N. N. Sørensen, "Comparison of the wake of different types of wind turbine CFD models," in American Institute of Aeronautics and Astronautics, AIAA Meeting Papers (2012), Vol. 4, pp. $3407-3417$.

${ }^{22}$ G. Crasto, A. R. Gravdahl, F. Castellani, and E. Piccioni, "Wake modeling with the actuator disc concept," Energy Procedia 24, 385-392 (2012).

${ }^{23}$ A. Sogachev, G. Menzhulin, M. Heimann, and J. Lloyd, "A simple three-dimensional canopy-planetary boundary layer simulation model for scalar concentrations and fluxes," Tellus 54, 784-819 (2002).

${ }^{24}$ L. Zhou, R. Gierens, A. Sogachev, D. Mogensen, J. Ortega, J. N. Smith, P. C. Harley, A. J. Prenni, E. J. T. Levin, A. Turnipseed, A. Rusanen, S. Smolander, A. B. Guenther, M. Kulmala, T. Karl, and M. Boy, "Contribution from biogenic organic compounds to particle growth during the 2010 BEACHON-ROCS campaign in a Colorado temperate needle leaf forest," Atmos. Chem. Phys. 15(15), 8643-8656 (2015).

${ }^{25}$ A. S. Monin and A. M. Yaglom, Statistical Fluid Mechanics (The MIT Press, 1971), Vol. 1, p. 453.

${ }^{26}$ T. Foken, "50 years Monin-Obukhov similarity theory," in 16th Symposium on Boundary Layers and Turbulence, Fundamental Studies of Turbulence: Observations, Theory, and Models Session (American Meteorological Society, Portland, ME, 2004), p. 7.1.

${ }^{27}$ J. Kaimal and J. J. Finnigan, Atmospheric Boundary Layer Flows (Oxford University Press, 1994), p. 304.

${ }^{28}$ S. Liu and X.-Z. Liang, "Observed diurnal cycle climatology of planetary boundary layer height," J. Clim. 23, 5790-5809 (2010).

${ }^{29}$ M. Kelly and S.-E. Gryning, "Long-term mean wind profiles based on similarity theory," Boundary-Layer Meteorol. 136, 377-390 (2010).

${ }^{30}$ ISO 9613-2:1996(E), Attenuation of Sound During Propagation Outdoors. Part 2: General Method of Calculation (International Organization for Standardization, 1996).

${ }^{31}$ K. Kaliski and E. Duncan, "Propagation modeling parameters for wind power projects," Sound Vib. 42(12), 12-14 (2008).

${ }^{32}$ J. Kragh and B. Plovsing, "Nord2000. Comprehensive outdoor sound propagation model. Part I-II," DELTA Acoustics and Vibration Report No. 1849-1851/00, 2000 (Danish Electronics, Light and Acoustics, 2001).

${ }^{33}$ E. Salomons, D. van Maercke, J. Defrance, and F. de Roo, "The harmonoise sound propagation model," Acta Acust. Acust. 97, 62-74 (2011).

${ }^{34}$ C. R. Hart, N. J. Reznicek, D. K. Wilson, C. L. Pettit, and E. T. Nykaza, "Comparisons between physics-based, engineering, and statistical learning models for outdoor sound propagation,” J. Acoust. Soc. Am. 139, 2640-2655 (2016).

${ }^{35} \mathrm{M}$. West, K. Gilbert, and R. A. Sack, "A tutorial on the parabolic equation (PE) model used for long-range sound propagation in the atmosphere," Appl. Acoust. 37, 31-49 (1992).

${ }^{36}$ D. K. Wilson, J. M. Noble, and M. A. Coleman, "Sound propagation in the nocturnal boundary layer," J. Atmos. Sci. 60, 2473-2486 (2003).

${ }^{37}$ E. Barlas, W. J. Zhu, W. Z. Shen, K. O. Dag, and P. J. Moriarty, "Consistent modelling of wind turbine noise propagation from source to receiver," J. Acoust. Soc. Am. 142, 3297 (2017).

${ }^{38}$ E. Barlas, W. J. Zhu, W. Shen, and S. J. Andersen, "Wind turbine noise propagation modelling: An unsteady approach," J. Phys.: Conf. Ser-- Sci. 753, 022003 (2016).

${ }^{39}$ E. Barlas, W. J. Zhu, W. Z. Shen, M. Kelly, and S. J. Andersen, "Effect of wind turbine wake on atmospheric sound propagation," Appl. Acoust. 122, 51-61 (2017).

${ }^{40}$ M. Kelly and I. Troen, "Probabilistic stability and "tall" wind profiles: Theory and method for use in wind resource assessment," Wind Energy 19, 227-241 (2016).

${ }^{41}$ A. Sogachev and M. Kelly, "Consistent two-equation closure modelling for atmospheric research: Buoyancy and vegetation implementations," Boundary-Layer Meteorol. 145, 307-327 (2012).

${ }^{42}$ D. C. Wilcox, Turbulence Modeling for CFD (DCW Industries, La Cañada, California, USA, 1994), p. 460.

${ }^{43}$ N. Troldborg, N. Sørensen, P.-E. Réthoré, and P. van der Laan, "A consistent method for finite volume discretization of body forces on collocated grids applied to flow through an actuator disk," Comput. Fluids 119, 197-203 (2015).

${ }^{44} \mathrm{~K}$. Attenborough, "Acoustical impedance models for outdoor ground surfaces," J. Sound Vib. 99, 521-544 (1985).

${ }^{45}$ K. Attenborough, "Sound propagation close to the ground," Annu. Rev. Fluid Mech. 34, 51-82 (2002).

${ }^{46}$ The temperature in the different runs varies from $16^{\circ}$ to $30^{\circ}$ along the propagation path of a receiver at $2 \mathrm{~m}$ height, but this results in only a $0.2 \mathrm{~dB}$ difference on the overall SPL, due to the source power levels dominated by the low frequencies.

${ }^{47}$ S. Oerlemans, P. Sijtsma, and B. M. López, "Location and quantification of noise sources on a wind turbine," J. Sound Vib. 299, 869-883 (2007).

${ }^{48}$ A. D. Pierce, Acoustics: An Introduction to Its Physical Principles and Applications (Acoustical Society of America through the American Institute of Physics, 1994), p. xxv+678.

${ }^{49}$ J. A. Businger, J. C. Wyngaard, Y. Izumi, and E. F. Bradley, "Flux-profile relationships in the atmospheric surface layer," J. Atmos. Sci. 28, 181-189 (1971).

${ }^{50}$ To correct this small effect, a factor of $\left(T_{0} / T_{0, \text { new }}\right)^{-1 / 2}$ could be used to scale the temperature gradients input to the PE propagation model.

${ }^{51}$ M. Kelly, I. Troen, and H. E. Jørgensen, "Weibull- k revisited: 'tall' profiles and height variation of wind statistics," Boundary-Layer Meteorol. 152, 107-124 (2014).

${ }^{52}$ J. G. Pedersen, S.-E. Gryning, and M. Kelly, "On the structure and adjustment of inversion-capped neutral atmospheric boundary-layer flows: Large-eddy simulation study," Boundary-Layer Meteorol. 153, 43-62 (2014). 